\title{
Information Will Be the Key to Successful Implementation
}

\section{Peter Littlejohns*}

King's College London, UK

\section{Kalipso Chalkidou}

NICE International and King's College London, UK

Making fair choices on the path to universal health coverage (WHO, 2014) is to be welcomed because tackling the relationship between cost-effectiveness and fairness has been given too little attention in policy-making. The consensus that universal coverage is a good thing quickly disperses as the concept is translated into working national policies and local delivery processes. As Weale (2014) and Rumbold and Wilson (2014) point out, seeking practical solutions can lead to the reexploration of previous givens and result in unexpected ethical and philosophical consequences. Whilst the basic premise underlying the discussion on the ethics of resource concurs with the view that equity is always at odds with efficiency, this is not inevitable as the authors of the report point out in their analysis - a view more fully explored by Culyer (2006). The present report is a welcome attempt to reconcile, as countries progress to UHC, ethical norms with the reality of setting priorities, involving what to pay for and under what circumstances.

\section{Starting from scratch}

The authors adopt a 'ground zero' approach (Bobadilla et al., 1994), starting from scratch to design an efficient and equitable system. But this is hardly ever a real world scenario. In reality, there is usually something in place, oftentimes funded through different channels. Every donor tends to support their favourite vertical programmes targeting diseases such as HIV or providing specific types of technology such as vaccines, and, in parallel, policy makers in the country may have allocated some resources to supporting vulnerable groups such as children and pregnant women, with a basic package of care. Introducing a fair and efficient package of services may therefore require significant shifting and reallocation of resources, including the disinvestment of existing services in order to reinvest and expand access'. Psychologists understand that "taking away" can be more problematic than "not giving" and the experience of most agencies seeking to achieve this have demonstrated that as controversial as denying approval or reimbursement for new 
technologies is reallocating resources away from existing technologies is even more difficult ( Garner and Littlejohns 2011) .

\section{Evidence is crucial}

Our view is that debates about balancing equity with efficiency in making resource allocation decisions (usually at the margin) can only be resolved, or (perhaps more realistically) explored, through the gathering of comprehensive information, including evidence on the clinical and cost effectiveness of the potential interventions for addressing the underlying epidemiology of a country's disease burden, and, most importantly, data on the impact of any decisions on patient and public health across different population groups. So often, even when the most robust systems are put in place, the consequences can be surprising unless kept under constant scrutiny (Weale and Littlejohns, 2014). In particular, evidence is required on the impact of the opportunity cost of applying equity constraints. In other words, decision makers need quantified estimates of health lost because of equity adjustments, estimates which may make a difference to their decision. This should concentrate initially in interventions and related costs and benefits that are health and healthcare related, though the identification and consistent application of a decision rule that reflects the budgetary constraint: what is often called the "threshold" (Culyer et al., 2007).

Vertical equity ought to apply not only to those whose disease or condition is considered but also to those likely to lose out because of a decision not to maximise health - the opportunity cost of the unknown patient. We acknowledge that this approach represents considerable computational, methodological and informational challenges but there are also risks of not doing so or of forging ahead with focusing on the health (and rights) of those well identified population groups at a cost to those who remain unknown (McCabe, Claxton and Culyer, 2008). Such tradeoffs are often ignored even by global organisations committed to equity such as the WHO as shown in their latest (2013) HIV/AIDS treatment guidelines (Revill et al. 2014).

\section{Politics is important too ....and inevitable}

Sensitivity to the political environment in which resource allocation decisions are made is essential in any country. Though committed to the realities of the political economy of priority setting, the authors use the word 'should' throughout the text which, perhaps, makes it sound all too easy to 
implement the authors' recommendations or, more likely, to fail to do so. Their designation of trade-offs as 'unacceptable' could come across as divorced from political reality, raising the question of 'unacceptable' to whom and why? While acceptance by politicians is essential, getting public acceptance of the approaches taken will also be required. The impact of patient and public involvement in clinical care has increased considerably over the last few years but the equivalent in policy decisions and particularly around prioritisation decisions requires further exploration and may be worth reflecting on at greater length in the report. Such a context-specific approach has perhaps been less emphasised by WHO, as reflected in its guidance products such as the Essential Medicines List or its guidelines on technologies (e.g. vaccines and diagnostics) and on management of diseases and conditions, such as mental health or the complications of pregnancy, that tend to be developed from its $\mathrm{HQ}$ in Geneva by committees of experts with limited representation (understandably given the practicalities of such an endeavour) by policy makers, administrators, frontline professionals and service users from the countries where such guidance will apply. However, as countries become more wealthy and governments more accountable, such a top down approach may have to be revisited.

\section{Calling for empirical research into what works in the ethics of priority setting}

Much work needs to be done on developing process indicators (referred to on page 50 of report) as metrics of success. This is a crucial and neglected area, despite the recent WHO/WB metrics work aimed at monitoring process towards UHC, which, though a step in the right direction, unfortunately makes no attempt at defining process and institutional maturity metrics (World Health Organization/The World Bank, 2013). The report does list, though too briefly in our view, a small number of process and structure metrics. It suggests, for example, that the presence of a designated institution (page 50) is a predictor of 'fair progressive realisation of UHC'. While this sounds sensible, more empirical evidence is needed that such an organisation is required. Perhaps there can be progress without such an organisation and lack of progress despite the presence of one. Japan for example lacks an institution for setting priorities and has managed to attain and sustain UHC, whilst Colombia has set up a series of priority-setting institutions (IETS being the latest) but is finding it difficult to link evidence and values to policy decisions about coverage. In another example, the report cites publicity as a condition for fulfilling procedural fairness (page 50). But is this enough? What other metrics of system maturity are there and how can we apply them or test them out using real country and regional level case studies? Given the paucity of empirical evidence in this 
field, the authors may have missed an opportunity retrospectively to apply some of their proposed indicators to countries such as Turkey or Thailand discussed in the report as good examples of transitioning to UHC, in order to assess their feasibility, relevance and usefulness.

A rapid and relatively inexpensive approach to gain information would be to develop a catalogue of successful (and unsuccessful) implementation case studies. For example, one could use the examples described in Box 3.4 of the report (reproduced in Voorhoeve, Ottersen and Norheim, 2014) as a starting point. Despite the fact dialysis is deemed to be the last thing a decision maker would consider covering (if at all), Thailand does cover dialysis as part of their UHC (Tantivess et al., 2013. Coming to another country example, Turkey is listed as a country with innovative systems of accountability and participation (page 47) but it does not have an established process for setting priorities despite their early successes in achieving universal coverage. So whether countries need to follow some high-income countries in linking transparency and with priority-setting, as the report seems to suggest, is an open question. It would be informative to think through why this is. Using the report's proposed framework and indicators, tested against real world examples, one could attempt to describe the trade-offs and the process by which decisions were made, as well as discuss the reasons and perhaps even their implications, where possible.

Practical solutions for exploring empirically the fairness dimension in priority setting for UHC could be explored in the context of real world practitioner-to-practitioner partnerships aiming at addressing similar questions on trade-offs and the methods and processes for making decisions on priorities. The Thai HITAP, the agency responsible for priority setting for the UHC in Thailand and NICE, its English counterpart informing decisions on coverage of services and technologies for the National Health Service, have been working with fellow policy makers from a wide range of countries, from Brazil and Colombia to Kazakhstan, Turkey, China, India and the Philippines, to help policy makers identify and act on their own priorities in a procedurally fair and evidence-informed way. The two organisations recently launched the international Decision Support Initiative with DFID, Rockefeller and BMGF support (See: http://www.cgdev.org/blog/nice-idea-priority-settingglobal-health-amanda-glassman and http://www.nice.org.uk/aboutnice/niceinternational/projects/NICEInternationalLaunchesInternatio nalDecisionSupportInitiative.jsp.) to help decision makers operating in settings with limited resources and expertise setting up the methods and processes of evidence informed policy making, using evidence adapted to their own setting linked to local values and local priorities. iDSI is about a practitioner-to-practitioner, public-public partnership, driven by demand and emphasising institutions and processes rather than imported technocratic one off solutions. 
With active pilots in Vietnam, the Philippines, China, India and Myanmar and new ones starting in South Africa and Indonesia, there is considerable scope for joint working to build, together with our colleagues from Ministries and Health Insurance Funds from around the world and start addressing, an empirical research agenda for the ethics of priority setting.

\section{A way forward}

We have identified a significant requirement for data collection and research. Unfortunately this type of trans-national policy orientated research rarely can attract significant resources and new systems need to be put in place. There are national examples of where health policy initiatives have linked to major research funders to address specific needs e.g., NICE in the UK (Longworth et al., 2009). The importance of understanding how UHC can be best achieved should encourage the WHO to work with major international and national research funders to identify and commission an ongoing research programme to learn and share the lessons for UHC roll out. 


\section{References}

Bobadilla, José-Luis, et al., (1994) 'Design, content and financing of an essential national package of health services', Bulletin of the World Health Organization, 72(4): 653.

Culyer, A. J. (2006) 'The bogus conflict between efficiency and vertical equity', Health Economics 15(11): 1155-58.

Culyer AJ., McCabe C, Briggs A, Claxton K, Buxton M, Akehurst R, Sculpher M, Brazier J. (2007) 'Searching for a threshold, not setting one: the role of the National Institute for Health and Clinical Excellence', Journal of Health Services Research and Policy. 12(1):56-8.

Garner S, Littlejohns P. Disninvestment from low value services: nicely done. BMJ 2011:343:d4519:1.1136/bmj.d4519.

Longworth, Louise et al., (2009) MRC-NICE Scoping Project: Identifying the National Institute For Health And Clinical Excellence's Methodological Research Priorities and an Initial Set of Priorities (University of York: Centre for Health Economics), CHE Research Paper 51, available at: https://www.york.ac.uk/che/pdf/rp51.pdf. (Last accessed 28.8.2014.)

McCabe, C., Claxton, K. and Culyer, A.J. (2008) 'The NICE cost-effectiveness threshold', Pharmacoeconomics 26(9): 733-744.

Revill, P. et al. (2014) WHO decides what is fair? International HIV treatment guidelines, social value judgements and equitable provision of lifesaving antiretroviral therapy (University of York: Centre for Health Economics), CHE Research Paper 99. Available at:

http://www.york.ac.uk/media/che/documents/papers/researchpapers/CHERP99 International HIV Guidelines ART.pdf. (Last accessed 28.8.2014).

Rumbold, Benedict and Wilson, James (2014) 'Reasonable Disagreement and the Generally Unaccptable'. This issue. 
Tantivess, Sripen, Pitsaphun Werayingyong, Piyatida Chuengsaman and Yot Teerawattananon (2013)

'Universal Coverage of Renal Dialysis in Thailand: Promise, Progress and Prospects', British Medical Journal, 346: f462 doi: http://dx.doi.org/10.1136/bmj.f462.

Vorhoeve, Alex, Ottersen, Trygve and Norheim, Ole (2014) 'Response to Our Critics'. This volume.

Weale, A. (2014) 'The Path from Nowhere?' This issue.

Weale, A. and Littlejohns, P. (2014) 'Why Is NICE Saying "Yes" So Often?', http://www.bmj.com/content/349/bmj.g4603/rapid-responses

Whitty JA, Burton P, Kendall E, Ratcliffe J, Wilson A, Littlejohns P, et al. (2014) 'Harnessing the potential to quantify public preferences for healthcare priorities through citizens' juries', International Journal of Health Policy Management, 3: 57-62.

World Health Organization (2014), Making fair choices on the path to universal health coverage. Geneva: World Health Organization. Available at http://apps.who.int/iris/bitstream/10665/112671/1/9789241507158 eng.pdf?ua=1. (Last accessed 27/07/14.

World Health Organization/The World Bank (2013) Monitoring Progress towards Universal Health Coverage at Country and Global Levels: A Framework, available at:

http://www.who.int/healthinfo/country monitoring evaluation/UHC WBG DiscussionPaper Dec2 013.pdf. (Last accessed 28.8.2014.)

\footnotetext{
* Correspondence to: Professor Peter Littlejohns, Professor of Public Health, Department of Primary Care and Public Health, King's College London, 5th Floor, Capital House, Guy's, SE1 3QD, London, UK. Email: peter.littlejohns@kcl.ac.uk.
} 